\title{
Research Notes
}

\section{A RAPID FAT TEST FOR FRIED PLANTAIN PRODUCTS'}

The determination of crude fat is a necessary quality control measure in the processing of fried products. One of the methods most generally used involves the extraction of the fat with anhydrous ether using a Soxhlet type extractor. ${ }^{2}$ As a quality control method, however, Soxhlet extraction is too slow and tedious requiring as much as 2 workdays. Ross and Treadway ${ }^{3}$ reported a simple method for fat determination using hexane as the solvent and requiring only about 15 minutes to complete. However, they did not compare the results obtained by this method with those using prolonged Soxhlet extraction. As the Soxhlet method for fat determination on fried products has been the standard procedure in our Laboratory, a study was conducted to determine the possibility of using the shorter Ross and Treadway method in our quality control work.

For this study experimental samples of fried plantain slices and extruded snacks were used. The two analytical methods were carried out as follows:

1. Soxhlet extraction-These analyses were made following the AOAC procedure for grain and stock feeds. Each sample was thoroughly mixed and moisture was determined by drying in vacuo at $60^{\circ}$ to $70^{\circ} \mathrm{C}$. The ether extraction was carried out on the dried weighed sample for a period of 16 hours using a Soxhlet-type extractor. The recovered ether extract was dried for 30 minutes at $100^{\circ} \mathrm{C}$, cooled, and weighed. Percent ether extract was determined.

2. Ross and Treadway extraction-The original method was modified by using exactly half the weight of the sample and the reagents. A $50-\mathrm{g}$ homogeneous sample was transferred to a Waring Blender, and $5 \mathrm{~g}$ of sodium chloride, $37.5 \mathrm{ml}$ of distilled water, $125 \mathrm{ml}$ of ethyl alcohol, and $112.5 \mathrm{ml}$ of hexane were added. The mixture was blended for 2 minutes at low speed and for 1 minute at high speed. The contents were filtered through glass wool in a Buchner funnel into a 250-ml graduated cylinder. After 2 minutes, the solids remaining in the glass wool were pressed lightly and the funnel removed. A $25-\mathrm{ml}$ aliquot from the upper layer containing the fat was transferred to a tared aluminum dish on an aluminum foil square. Ten $\mathrm{ml}$ of alcohol were added to the dish and the contents were ignited.

1 Manuscript submitted to Editorial Board August 8, 1973.

2 Official Methods of Analysis of the Association of Official Agricultural Chemists, 10th ed., Washington, D.C., Sec. 22.033, 1965.

'Ross, L. R., and Treadway, R. H., A New and Rapid Method for Determining Fat in French Fried Potatoes, Amer. Potato J. 39: 207, 1962. 
After combustion and cooling, the dish and foil were reweighed. The weight difference was multiplied by 9 to obtain percent hexane extract.

To compare the relative precision of the Ross and Treadway method with the Soxhlet extraction, 12 samples from a single batch of extruded fried plantain sticks were analyzed by both methods and the means and coefficients of variation were calculated. To further determine the usefulness of the rapid method for estimating fat content, samples from 18 additional batches of fried plantain sticks and slices were analyzed by the two methods and a simple correlation study was performed.

Statistical analysis of the data indicates a highly significant difference between the methods, but the reproducibility of both is practically the same, as shown in the following tabulation from fat analyses of 12 samples by each method:

\begin{tabular}{llc}
\multicolumn{1}{c}{ Method } & $\begin{array}{c}\text { Mean } \\
\text { (percent) }\end{array}$ & $\begin{array}{c}\text { Coefficient of } \\
\text { variation } \\
\text { (percent) }\end{array}$ \\
Soxhlet & 38.73 & 2.63 \\
Ross and Treadway & 31.33 & 2.62
\end{tabular}

A highly significant difference between the methods was expected, and can be accounted for by the differences in the extraction capacity of each solvent, the time of contact between the solvent and the sample, and the proportion of solvent to sample weight in the two methods. Ignition of the sample in the Ross and Treadway method was found to have no effect on the results when compared to evaporation of the solvent at room temperature, or by using a hot plate. An additional and important source of variation arises from an error involved in the calculation as used by Ross and Treadway. By multiplying the weight of fat recovered by the constant factor of 9 , it is assumed that the fat in the sample once extracted is not going to alter the volume of solvent from which the final aliquot is taken. This error will be larger as the fat content in the sample increases. If the change in volume of the hexane layer is measured and accounted for in the calculation, the difference between the results obtained by the two methods will be reduced.

There is a significant linear correlation $(r=0.96)$ between the methods. The equation calculated for use in predicting Soxblet ether values from rapidly determined hexane values is,

$$
Y=1.2637 X-0.5449 \text {, }
$$

where $Y$ is the estimated Soxhlet value and $X$ is the value as determined by hexane extraction.

From these results it can be concluded that the fast hexane determina- 
tion of Ross and Treadway can be used with high precision to estimate the fat content of fried plantain products. Besides being rapid, this method uses simple inexpensive equipment available in any laboratory. It is therefore recommended as a quality control test for fat determination in fricd plantain products. 